\title{
A rare case of multiple hereditary exostoses with spinal cord compression
}

\author{
Susima Pallemulla ${ }^{1}$, Sujeewa Amarasena ${ }^{2}$, Saman Wadanamby ${ }^{3}$ \\ ${ }^{1}$ Registrar in Paediatrics, ${ }^{3}$ Consultant Neurosurgeon, Teaching Hospital, Karapitiya. \\ ${ }^{2}$ Professor of Paediatrics, Faculty of Medicine, University of Ruhuna, Galle
}

A nine year-old previously well child presented with weakness of both lower limbs of 9 months duration. He developed numbness and weakness of the right lower limb 9 months back. Then the child was admitted to General Hospital, Matara and was investigated. The child went home prematurely before the completion of investigations and defaulted follow-up due to multiple social problems. Six weeks later he developed weakness of the left lower limb as well. Weakness of limbs progressed slowly over the next few months and he became bed-bound with paraplegia. He had urinary and faecal incontinence. As a result of his illness he was unable to attend the school and stopped schooling completely. There was a family history of multiple hereditary exostoses (HME) in the father, younger sister, and a paternal aunt. The family was affected by Tsunami in 2004 and shifted residence. The father was jailed for 
suspected murder. The mother was unable to cope with the illness of the child, the father's imprisonment and the post tsunami problems like housing and feeding the other children. Therefore, she did not seek medical care for the child.

The child was having grade 0 power in both lower limbs with exaggerated reflexes, clonus and bilateral extensor plantar responses. There was a mild weakness of the left hand grip. The sensory level was at $T_{6}$ level. Rest of the neurological examination was normal.

General examination revealed multiple exostoses of the body, mainly on femur, tibia and humerus. MRI scan of the cervical and thoracic spine was done. A bony growth compressing the spinal cord at T3 level almost bisecting the cord was found (Figure 1). Neurosurgery was performed with a laminectomy and excision of the bony growth resulting in decompression of the cord. Within 1 week of the surgery the child was able to stand with support despite bilateral tendo-Achilles contractures. Even some bladder and bowel sensation has returned. He was trained in clean intermittent catheterization and a rehabilitation programme was arranged with physiotherapy and a wheelchair. Due to the poor social support setup, a nongovernmental organization (NGO) took over the responsibility of providing a wheelchair and physiotherapy.

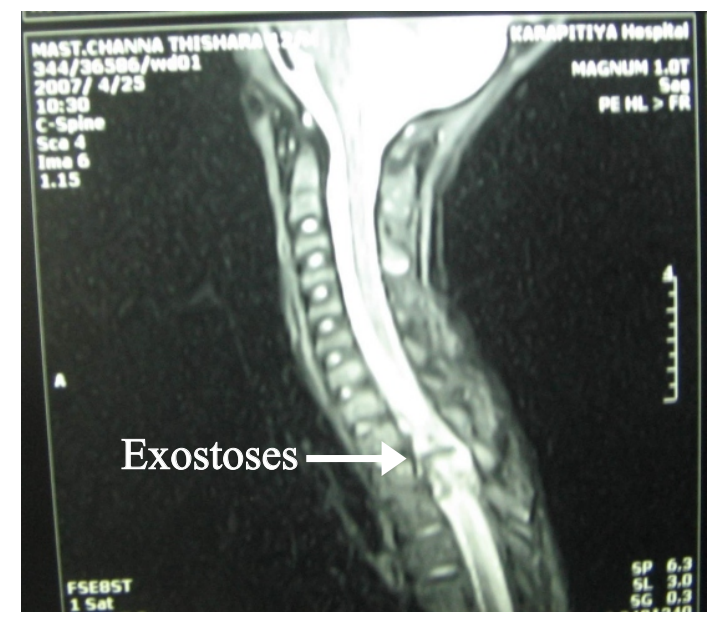

Figure 1 - MRI scan of the cervical and thoracic spine

\section{Discussion}

HME is an autosomal dominant disorder in which multiple osteochondromas arise from the surface of bones. It is the commonest bone tumor and it can affect any bone preformed in cartilage. Generally it occurs in the periphery of the most rapidly growing ends of long bones [1]. Patients with HME may have 2-100 osteochondromas. Most are solitary osteochondromas discovered incidentally in children and adolescents. Exostoses usually appear in the childhood between 2-10 years of age. Exostoses usually grow until the growth plates are open and their growth ceases with the skeletal maturity. Rarely spontaneous resolution occurs during the childhood [2].

HME is associated with complications like short stature, limb length inequality, limb deformities and scoliosis. They may undergo malignant transformation (1-20\%). Tendons, nerves, blood vessels may get trapped around the osteochondromas leading to symptoms. Visceral injuries and luminal obstruction may occur with inwardly growing osteochondromas.

Spinal cord compression is an extremely rare complication of HME. Few cases had been reported and they have presented in the second decade of life and mainly in the thoracic region. MRI or CT is the investigation of choice for an early diagnosis. Early surgical decompression with laminectomy results in excellent functional neurological recovery $[3,4]$. But with the delay in presentation and surgery, residual neurological impairment can occur [5].

Other aspects to highlight in this case are lack of a good social service in our country which can attend to problems of children like this resulting in compromised health status. This lack generally affects the poorer segments of the society. We depend on well-wishers and NGOs for their goodwill to provide proper care for such children instead of an organized social security system from the government. 


\section{References}

1. Richard E. Behrman, Robert M. Kleigman, Hal B. Jenson. In: Nelson Textbook of Pediatrics, $17^{\text {th }}$ edition.

2. Ali Nawaz Khan. Osteochondroma and Osteochondromatosis,

www.emedicine.com/radio/topic496htm
3. Mermer M.J, Gupta M.C et al. Thoracic vertebral body exostosis as a course of a myelopathy in a patient with HME. J. Spinal Disord Tech. 2002 Apr.15(2): 144-8.

4. Oga M, Nakarani F et al. Treatment of cervical cord compression caused by HME with laminoplasty. Spine 2000 May 15;25(10):1290-2 .

5. Faik A, Mahfoud Filali S. et al. Spinal cord compression due to vertebral osteochondromatosis. Joint Bone spine 2005 Mar; 72 (2):177-9 